\title{
Is There a Future for Interleukin 17 Blocking Agents in Rheumatoid Arthritis?
}

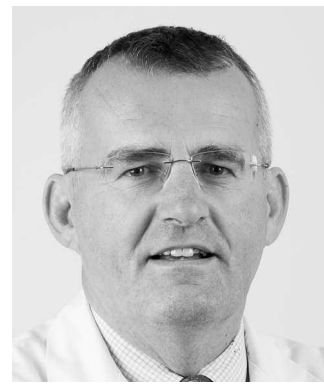

Rheumatoid arthritis (RA) is a chronic inflammatory disease characterized by synovitis leading to the progressive destruction of the joints and irreversible disability. The pathophysiology of the disease is complex with various groups of immune and joint cells, soluble mediators, and autoantibodies identified to participate in the pathogenesis. Different animal models have provided a better understanding of the altered immune functions and regulation in RA. In such models, recent research has focused on Th17 cells and interleukin (IL) 17 production to demonstrate a central role in the synovitis and the destruction of joint and bone ${ }^{1}$. However, the extrapolation of the immunopathology of RA animal models to human diseases remains controversial. In recent years, our knowledge about the pathomechanisms of RA has expanded to such a degree that specific therapies targeting various cells or soluble mediators of inflammation have been developed. Tumor necrosis factor- $\alpha$ (TNF- $\alpha$ ) has been largely described in the literature as a key player in RA, but the ongoing demonstration of the involvement of other mediators gives us alternative treatment options. T cells are another important target in autoimmune diseases such as RA, as confirmed by the effective use of abatacept, an agent that selectively blocks $\mathrm{T}$ cell costimulation ${ }^{2}$. Recently, studies in RA have demonstrated that $\mathrm{T}$ cells, including Th17 cells, infiltrate the joints and that IL-17 promotes osteoclastogenesis, suggesting an appropriate target ${ }^{3}$.

In their article published in this issue of The Journal, Tlustochowicz and colleagues report the outcome of a phase II study using secukinumab, a human monoclonal IgG1 that targets IL-17A in patients with inadequate response to methotrexate $(\mathrm{MTX})^{4}$. Different loading regimens were compared but none was significantly better than placebo after 12 weeks. In a previous phase II study, the primary efficacy endpoint, ACR20 (American College of Rheumatology 20\% improvement), was also not achieved; however, it was demonstrated in the extension study that patients with improved C-reactive protein (CRP) and 28-joint Disease Activity Score (DAS28) sustained their responses after 1 year $^{5,6}$. No important safety signals were reported. Other IL-17 blocking agents such as ixekizumab or brodalumab failed to demonstrate broad efficacy in $\mathrm{RA}^{7,8}$.
Although these results are disappointing, we cannot conclude that IL-17 blocking agents are totally ineffective in RA because a subgroup of patients with RA experienced significant efficacy without toxicity. There are some similarities between anti-IL-17 and anti-IL-1 drug development. Blocking IL-1 is less effective than anti-TNF but is very safe and could be very important to prevent cartilage loss. In anakinra trials, clinical efficacy was moderate, but joint space narrowing was reduced to the same degree as with infliximab $^{9}$. The effect benefits of canakinumab on the ACR and DAS scores are viewed as "modest or even mild" compared to anti-TNF ${ }^{10}$. But other aspects of the drug profile, such as longterm efficacy and safety, were not reported and published in longterm extension studies.

In a recent publication, Burmester, et al, reported that secukinumab was significantly more effective than placebo in reducing DAS28-CRP and producing ACR20 responses at Week $12^{11}$. In this phase II study, the hypothesis of clinical utility for HLA-DRB1* allelic groups in RA anti-IL-17A short-term response prediction could not be corroborated. Identification of a biomarker to predict better response and good tolerance is an important objective in a heterogeneous disease such as RA. Even with the use of the best potent agent in RA such as TNF antagonists, studies indicate that about $25 \%$ to $30 \%$ of patients treated do not display any significant clinical improvement. Yet the identification of poor responders prior to initiation of therapy would direct the use of alternative methods of treatment, thereby preventing disease progression in these patients and saving unnecessary costs. Several studies, aimed at the identification of prognostic markers of response to biologics in RA, were recently published but were not conclusive ${ }^{12}$. The inflammatory mechanisms targeted by biological agents are located in the synovium, and gene expression profiles of RA peripheral blood mononuclear cells are less instructive and not representative of these synovial-tissue-specific pathways. Clinicians would be interested in measurable variables that could predict response to therapies prior to initiation rather than in modifications of gene expression during therapy. Lauwerys, et al from our group have published markers of synovial gene expression after different biological agents,

See Efficacy and safety of secukinumab in RA, page 495

Personal non-commercial use only. The Journal of Rheumatology Copyright (C) 2016 . All rights reserved. 
including adalimumab, rituximab, and tocilizumab ${ }^{13}$. This approach for anti-IL-17 could be supported by data published by van Baarsen, who reported a heterogeneous expression of IL-17 in the synovium ${ }^{14}$. Personalized medicine is at this time a dream, but the validation of synovial tissue predictive markers is one of the most important fields of RA research.

The IL-23/Th17 axis is currently considered a main road involved in spondyloarthritis ${ }^{15}$. Secukinumab improved signs and symptoms of the disease. Improvement was also clear in physical function, quality of life, and magnetic resonance imaging (MRI) inflammatory scores, with a fair safety profile so $\mathrm{far}^{16}$. In a recent phase II study in psoriatic arthritis, secukinumab was more effective than placebo, which validates IL-17A as a therapeutic target ${ }^{17}$. Why is secukinumab effective in spondyloarthritis and psoriatic arthritis and not in RA? A specific role of Th17 and IL-17 in enthesitis and axial disease has been reported, but could this mean better efficacy in peripheral arthritis? Probably not. On the other hand, anti-IL-6 and MTX have failed to demonstrate efficacy in spondyloarthropathies but their efficacy in peripheral arthritis is well accepted.

In clinical trials, minimal response in RA could be explained by the primary objective selection, the dose, or the placebo responses, and the selected population. Because the studies of secukinumab in RA addressed only chronic patients refractory to MTX and/or biologics, we could speculate that targeting IL-17 could be more effective in the early phase of RA. Targeting T cells with the use of abatacept in early RA is very effective, and authors have reported an increased proportion of CCR6+ Th17 cells in the peripheral blood of patients with early recent untreated $\mathrm{RA}^{18,19}$. Therefore, a trial with an early induction therapy of IL-17 blocking agents could be very interesting.

Regulatory guidance (e.g., US Food and Drug Administration Guidance to Industry ${ }^{20}$ ) for the development of new drugs in RA is more strict, and the chance to achieve a better response than anti-TNF is limited. Now, head-to-head trials are recommended in phase III. Combinations of biological drugs such as anti-TNF and anti-IL-17 could be an option but are probably not realistic for safety and economic reasons. $\mathrm{RA}$ is a heterogeneous disease, and remission is not achievable in a large group of patients. Data reported from the present study ${ }^{4}$ should not end anti-IL-17 development in RA. Further innovative studies such as early induction and treatment capacity prediction of biomarkers are needed.

\section{PATRICK DUREZ, MD,}

Pôle de pathologies rhumatismales, Institut de Recherche Expérimentale et Clinique, Université catholique de Louvain; and Department of Rheumatology, Cliniques Universitaires Saint-Luc, Brussels, Belgium.

Address correspondence to Dr. P. Durez;

E-mail: Patrick.Durez@uclouvain.be

\section{REFERENCES}

1. Benedetti G, Miossec P. Interleukin 17 contributes to the chronicity of inflammatory diseases such as rheumatoid arthritis. Eur J Immunol 2014;44:339-47.

2. Genovese MC, Tena CP, Covarrubias A, Leon G, Mysler E, Keiserman M, et al. Subcutaneous abatacept for the treatment of rheumatoid arthritis: longterm data from the ACQUIRE trial. J Rheumatol 2014;41:629-39.

3. Lubberts E, Koenders MI, van den Berg WB. The role of T-cell interleukin-17 in conducting destructive arthritis: lessons from animal models. Arthritis Res Ther 2005;7:29-37.

4. Tlustochowicz W, Rahman P, Seriolo B, Krammer G, Porter B, Widmer A, et al. Efficacy and safety of subcutaneous and intravenous loading dose regimens of secukinumab in patients with active rheumatoid arthritis: results from a randomized phase II study. J Rheumatol 2016;43:495-503.

5. Genovese MC, Durez P, Richards HB, Supronik J, Dokoupilova E, Mazurov V, et al. Efficacy and safety of secukinumab in patients with rheumatoid arthritis: a phase II, dose-finding, double-blind, randomised, placebo controlled study. Ann Rheum Dis 2013;72:863-9.

6. Genovese MC, Durez P, Richards HB, Supronik J, Dokoupilova E, Aelion JA, et al. One year efficacy and safety results of secukinumab in patients with rheumatoid arthritis: phase II, dose-finding, double-blind, randomised, placebo-controlled study. J Rheumatol 2014;41:414-21.

7. Genovese MC, Greenwald M, Cho CS, Berman A, Jin L, Cameron GS, et al. A phase II randomized study of subcutaneous ixekizumab, an anti-interleukin-17 monoclonal antibody, in rheumatoid arthritis patients who were naive to biologic agents or had an inadequate response to tumor necrosis factor inhibitors. Arthritis Rheumatol 2014;66:1693-704.

8. Pavelka K, Chon Y, Newmark R, Lin SL, Baumgartner S, Erondu N. A study to evaluate the safety, tolerability, and efficacy of brodalumab in subjects with rheumatoid arthritis and an inadequate response to methotrexate. J Rheumatol 2015;42:912-9.

9. Zwerina J, Hayer S, Tohidast-Akrad M, Bergmeister H, Redlich H, Feige U, et al. Single and combined inhibition of tumor necrosis factor, interleukin-1, and RANKL pathways in tumor necrosis factor-induced arthritis: effects on synovial inflammation, bone erosion, and cartilage destruction. Arthritis Rheum 2004;50:277-90.

10. Alten R, Gomez-Reino J, Durez P, Beaulieu A, Sebba A, Krammer $\mathrm{G}$, et al. Efficacy and safety of the human anti-IL-1 $\beta$ monoclonal antibody canakinumab in rheumatoid arthritis: results of a 12-week, Phase II, dose-finding study. BMC Muskuloskelet Disord 2011;12:153.

11. Burmester GR, Durez P, Shestakova G, Genovese MC, Schulze-Koops H, Li Y, et al. Association of HLA-DRB1 alleles with clinical responses to the anti-interleukin-17A monoclonal antibody secukinumab in active rheumatoid arthritis. Rheumatology 2016;55:49-55.

12. Cuppen BV, Welsing PM, Sprengers JJ, Bijlsma JW, Marijnissen AC, van Laar JM, et al. Personalized biological treatment for rheumatoid arthritis: a systematic review with a focus on clinical applicability. Rheumatology 2015;pii:kev421.

13. Lauwerys B, Hernández-Lobato D, Gramme P, Ducreux J, Dessy A, Focant I, et al. Heterogeneity of synovial molecular patterns in patients with arthritis. PLoS One 2015;10:e0122104.

14. Van Baarsen LG, Lebre MC, van der Coelen D, Aarrass S, Tang MW, Ramwadhdoebe TH, et al. Heterogeneous expression pattern of interleukin 17A (IL-17A), IL-17F and their receptors in synovium of rheumatoid arthritis, psoriatic arthritis and osteoarthritis: possible explanation for nonresponse to anti-IL-17 therapy? Arthritis Res Ther 2014;16:426.

15. Kenna TJ, Davidson SI, Duan R, Bradbury LA, McFarlane J, Smith

Personal non-commercial use only. The Journal of Rheumatology Copyright (C) 2016. All rights reserved 
M, et al. Enrichment of circulating interleukin-17-secreting interleukin-23 receptor-positive $\gamma / \delta \mathrm{T}$ cells in patients with active ankylosing spondylitis. Arthritis Rheum 2012;64:1420-9.

16. Baeten D, Sieper J, Braun J, Baraliakos X, Dougados M, Emery P, et al. Secukinumab, an interleukin-17A inhibitor, in ankylosing spondylitis. N Engl J Med 2015;373:2534-48.

17. Mease PJ, McInnes IB, Kirkham B, Kavanaugh A, Rahman P, van der Heijde D, et al. Secukinumab inhibition of interleukin-17A in patients with psoriatic arthritis. N Engl J Med 2015;373:1329-39.

18. Emery P, Durez P, Dougados M, Legerton CW, Becker JC, Vratsanos G, et al. Impact of T-cell costimulation modulation in patients with undifferentiated inflammatory arthritis or very early rheumatoid arthritis: a clinical and imaging study of abatacept (the ADJUST trial). Ann Rheum Dis 2010;69:510-6.
19. Van Hamburg JP, Asmawidjaja PS, Davelaar N, Mus AM, Colin EM, Hazes MW, et al. Th17 cells, but not Th1 cells, from patients with early rheumatoid arthritis are potent inducers of matrix metalloproteinases and proinflammatory cytokines upon synovial fibroblast interaction, including autocrine interleukin-17A production. Arthritis Rheum 2011;63:73-83.

20. U.S. Department of Health and Human Services. Guidance for industry rheumatoid arthritis: developing drug products for treatment. 2013. [Internet. Accessed January 6, 2016.] Available from: www.fda.gov/downloads/Drugs/GuidanceCompliance RegulatoryInformation/Guidances/UCM354468.pdf

J Rheumatol 2016;43:465-7; doi:10.3899/jrheum.160010 